University of Nebraska - Lincoln

DigitalCommons@University of Nebraska - Lincoln

Biochemistry -- Faculty Publications

Biochemistry, Department of

December 1999

\title{
Melanoma chondroitin sulphate proteoglycan regulates cell spreading through Cdc42, Ack-1 and p130
}

\author{
Kathryn M. Eisenmann \\ University of Minnesota, Minneapolis, Minnesota \\ James B. McCarthy \\ University of Minnesota, Minneapolis, Minnesota \\ Melanie A. Simpson \\ University of Nebraska - Lincoln, msimpson2@unl.edu \\ Patricia J. Keely \\ University of Wisconsin, Madison, Wisconsin \\ Jun-Lin Guan \\ Cornell University, Ithaca, New York
}

See next page for additional authors

Follow this and additional works at: https://digitalcommons.unl.edu/biochemfacpub

Part of the Biochemistry, Biophysics, and Structural Biology Commons

Eisenmann, Kathryn M.; McCarthy, James B.; Simpson, Melanie A.; Keely, Patricia J.; Guan, Jun-Lin; Tachibana, Kouichi; Lim, Louis ; Manser, Ed; Furcht, Leo T.; and lida, Joji, "Melanoma chondroitin sulphate proteoglycan regulates cell spreading through Cdc42, Ack-1 and p130 cas" (1999). Biochemistry -- Faculty Publications. 18.

https://digitalcommons.unl.edu/biochemfacpub/18

This Article is brought to you for free and open access by the Biochemistry, Department of at DigitalCommons@University of Nebraska - Lincoln. It has been accepted for inclusion in Biochemistry -- Faculty Publications by an authorized administrator of DigitalCommons@University of Nebraska - Lincoln. 


\section{Authors}

Kathryn M. Eisenmann, James B. McCarthy, Melanie A. Simpson, Patricia J. Keely, Jun-Lin Guan, Kouichi

Tachibana, Louis Lim, Ed Manser, Leo T. Furcht, and Joji lida 


\title{
Melanoma chondroitin sulphate proteoglycan regulates cell spreading through Cdc42, Ack-1 and p130 cas
}

\author{
Kathryn M. Eisenmann*, James B. McCarthy*ł\$\$, Melanie A. Simpson*, Patricia J. Keely", \\ Jun-Lin Guan", Kouichi Tachibana**, Louis Lim ${ }^{\dagger+}$, Ed Manser ${ }^{\ddagger \neq}$, Leo T. Furcht ${ }^{* \dagger}$, and Joji lida* \\ * Department of Laboratory Medicine and Pathology, University of Minnesota, Minneapolis, Minnesota 55455, USA \\ $\dagger$ Biomedical Engineering Institute, University of Minnesota, Minneapolis, Minnesota 55455, USA \\ ¥ Cancer Center, University of Minnesota, Minneapolis, Minnesota 55455, USA \\ ๆ Department of Pharmacology, University of Wisconsin, Madison, Wisconsin 53706, USA \\ \# Department of Molecular Medicine, Cornell University, Ithaca, New York 14853, USA \\ ** Department of Cancer Immunology and AIDS, Harvard Medical School, Boston, Massachusetts 02115, USA \\ t† Institute of Neurology, London WC1N 1PJ, UK

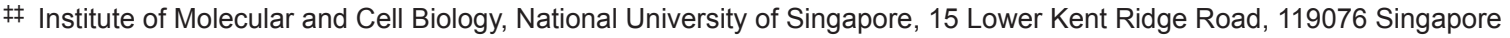 \\ $\S$ Corresponding author: James B. McCarthy, email: mccar001@tc.umn.edu
}

\begin{abstract}
Melanoma chondroitin sulphate proteoglycan (MCSP) is a cell-surface antigen that has been implicated in the growth and invasion of melanoma tumors. Although this antigen is expressed early in melanoma progression, its biological function is unknown. MCSP can stimulate the integrin- $\alpha_{4} \beta_{1}$-mediated adhesion and spreading of melanoma cells. Here we show that stimulated MCSP recruits tyrosine-phosphorylated $\mathrm{p} 130^{\mathrm{cas}}$, an adaptor protein important in tumor cell motility and invasion. MCSP stimulation also results in a pronounced activation and recruitment of the Rho-family GTPase Cdc42. MCSP-induced spreading of melanoma cells is dependent upon active Cdc42, a Cdc42-associated tyrosine kinase (Ack-1) and tyrosine phosphorylation of p130 cas. Furthermore, vectors inhibiting Ack-1 or Cdc42 expression and/or function abrogate MCSP-induced tyrosine phosphorylation and recruitment of $\mathrm{p} 130^{\mathrm{cas}}$. Our findings indicate that MCSP may modify tumor growth or invasion by a unique signal-transduction pathway that links Cdc42 activation to downstream tyrosine phosphorylation and subsequent cytoskeletal reorganization.
\end{abstract}

$\mathrm{M}$ etastasis of tumor cells requires rapid, dynamic regulation of cell-surface adhesion receptors important for migration, invasion, extravasation and growth. One group of proteins involved in tumor adhesion is the integrins, a family of heterodimeric adhesion receptors fundamentally important to mediating cell-cell and cellextracellular matrix (ECM) interactions ${ }^{1}$. In particular, integrin $\alpha_{4} \beta_{1}$ has been implicated in tumor cell invasion and metastasis ${ }^{2,3}$. Although integrin $\alpha_{4} \beta_{1}$ is expressed in a variety of malignancies, such as melanoma ${ }^{4,5}$, and $\alpha_{4} \beta_{1}$ expression has been linked to melanoma progression6, the mechanism by which tumor cells modulate integrin adhesiveness is not fully understood. However, clustering of integrins triggers a cascade of intracellular signalling pathways leading to the phosphorylation of cytoplasmic and cytoskeletal substrates, such as focal adhesion kinase (FAK), paxillin and p130 cas (refs 1, 7-9). Furthermore, both $\mathrm{p} 130^{\text {cas }}$ and FAK play a part in integrinmediated tumor cell migration ${ }^{10,11}$, indicating that modifying integrin signalling pathways may stimulate tumor invasion and metastasis.

Cell-surface proteoglycans are a second group of adhesion receptors that mediate both cell-cell and cell-ECM interactions ${ }^{12}$. Many ECM proteins contain closely spaced proteoglycan- and integrinbinding domains, indicating that these two distinct types of adhesion receptor may generally function in concert to stimulate cytoskeletal reorganization, migration and invasion. Of the proteoglycans, MCSP is abundantly and ubiquitously expressed on most human melanoma cells, whereas its expression is lower on normal melanocytes ${ }^{13}$. MCSP may be involved in the spreading, migration and invasion of melanoma cells, as antibodies directed against MCSP inhibit these processes in vitro ${ }^{14,15}$. We have shown previously that MCSP enhances $\alpha_{4} \beta_{1}$ integrin function ${ }^{16-19}$, in part by stimulating signalling pathways involving tyrosine kinases ${ }^{17}$.
Members of the Rho family of GTPases, Rho, Rac and Cdc42, regulate cytoskeletal rearrangements, leading to the formation of actin stress fibres, lamellipodia and filopodia, respectively ${ }^{20,21}$. The cooperative signalling of integrin and syndecan proteoglycan that leads to the assembly of focal adhesions has been shown to be Rho dependent ${ }^{22}$. Integrin- $\beta_{1}$-mediated signalling has also been linked to cytoskeletal rearrangements through functional interactions of Cdc42 with phosphatidylinositol-3-OH kinase $(\mathrm{PI}(3) \mathrm{K})$ and potentially FAK23,24, indicating that Rho-family GTPases may be responsible for regulating adhesive signals mediated by both integrins and cellsurface proteoglycans.

Members of the Ack (activated-Cdc42-associated kinase) family of non-receptor tyrosine kinases act as potentially important links between certain activated Rho-family GTPases (such as Cdc42) and signalling pathways. Members of this family interact specifically with the GTP-bound (active) form of Cdc42 (refs 25, 26). Ack-1 is homologous to FAK in its kinase and proline-rich domains, as well as to Src in its kinase and Src homology 3 (SH3) domains ${ }^{25}$, indicating that Ack-1 may interact with, and phosphorylate, effector proteins similar to those that interact with FAK and Src. Ack-2 is a structural variant of Ack-1; it lacks 344 residues within the proline-rich carboxy-terminal tail ${ }^{25}$. Activated Ack- 2 coprecipitates with $\beta_{1}$ integrin $^{27}$, suggesting a role for this family of kinases in modulating cell adhesion.

We show here that clustering of MCSP activates Cdc42 to a GTP-bound state. Furthermore, activated MCSP recruits a signalling complex that includes activated Cdc42 and Ack-1. Formation of this complex results in recruitment and tyrosine phosphorylation of p130 cas and subsequently enhances $\alpha_{4} \beta_{1}$-integrin-mediated melanoma cell spreading. 

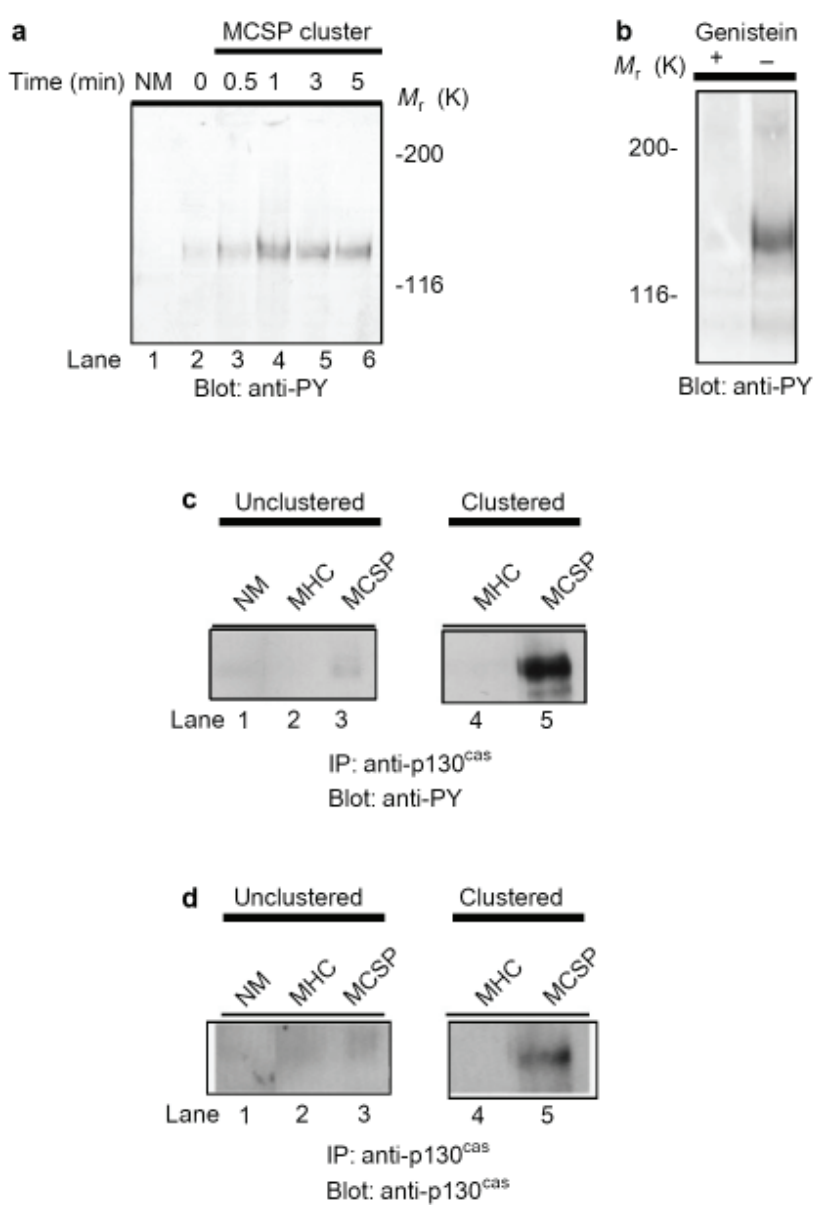

Figure 1 MCSP clustering induces tyrosine phoshorylation of p130cas . NM, immunoprecipitation with mouse $\operatorname{lgG}$. a, Clustering of MCSP induces tyrosine phosphorylation of a protein of $M_{\mathrm{r}} 130 \mathrm{~K}$ ( $\mathrm{p} 130$ ) in a time-dependent manner. $\mathbf{b}, \mathrm{MCSP}$-induced tyrosine phosphorylation of $p 130$ is sensitive to the tyrosine kinase inhibitor genistein. c, d, MCSP clustering is required for tyrosine phosphorylation (c) and recruitment (d) of $p 130^{\text {cas }}$. In $\mathbf{c}, \mathbf{d}$, lanes 1-3 depict unclustered samples in which cells were initially lysed and immunoprecipitated with mouse lgG (NM) or monoclonal antibodies against class I MHC or MCSP. Immunoprecipitates were released and re-immunoprecipitated with anti-p130cas monoclonal antibody (c, d) and then blotted with antibody against phosphorylated tyrosine (c) or p130cas (d). Lanes 4, 5 show cells that were incubated with either anti-MHC or anti-MCSP-coated beads to cluster the antigen. Cells were then lysed, and MHC- or MCSP-associated proteins were re-immunoprecipitated with anti-p130cas monoclonal antibody and then blotted with antibody against phosphorylated tyrosine (c) or p130 cas (d). PY, phosphorylated tyrosine.

\section{Results}

MCSP clustering induces tyrosine phosphorylation of a p130 protein. We have shown previously that cooperative stimulation of both MCSP and $\alpha_{4} \beta_{1}$ integrin induces cell spreading and focal-contact formation in A375SM human melanoma cells ${ }^{17}$. The cytoskeletal rearrangements delineating this morphology were, in part, dependent upon tyrosine kinases, as shown by an inhibition of melanoma cell spreading and focal-contact formation upon pretreatment with a tyrosine kinase inhibitor, genistein ${ }^{17}$. Hence, we have now evaluated a role for tyrosine phosphorylation in MCSP-induced signalling pathways. Signal transduction was stimulated in A375SM human melanoma cells by addition of magnetic beads coated with 9.2.27, a monoclonal antibody directed towards the MCSP core protein. MCSP and its associated proteins were separated by SDS-polyacrylamide gel electrophoresis (SDS-PAGE) and immunoblotted. Blots probed with anti-phosphotyrosine monoclonal antibodies showed a protein migrating at relative molecular mass $130,000\left(M_{\mathrm{r}} 130 \mathrm{~K}\right.$; p130) (Figure 1a). Tyrosine phosphorylation of p130 was specific and occurred
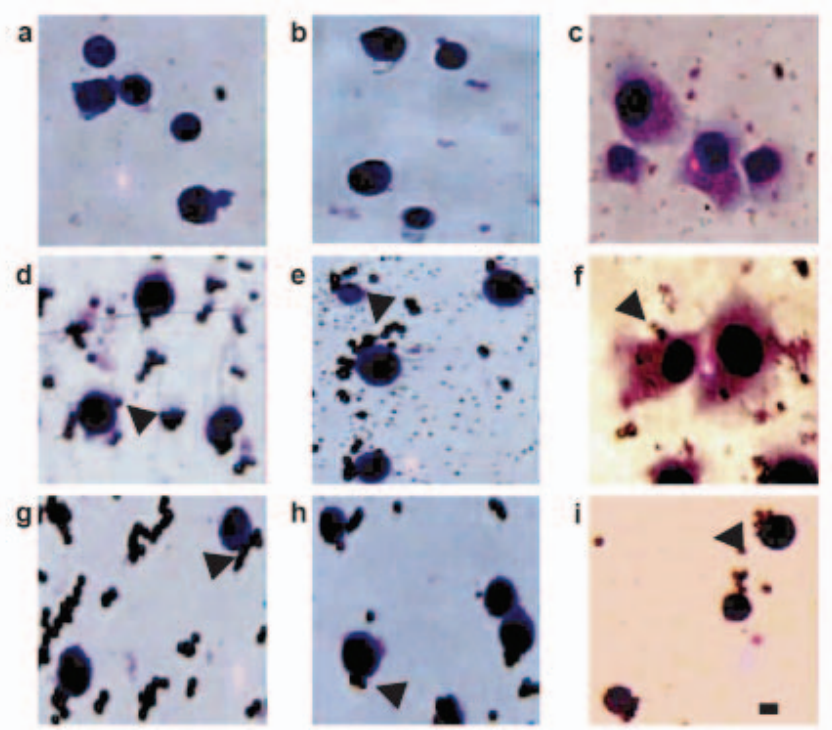

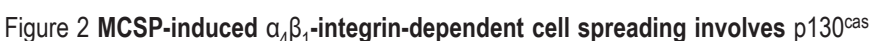
signalling. Untransfected $(\mathrm{a}-\mathrm{c})$ or A375SM cells transfected with vector alone (df) or $\mathrm{p} 130^{\text {cas }} \mathrm{SH} 3$ vector $(\mathbf{g}-\mathbf{i})$ were allowed to adhere and spread for $1 \mathrm{~h}$ on plates coated with rlllcs $(\mathbf{a}, \mathbf{d}, \mathbf{g})$, monoclonal antibody 9.2.27 (b,e, h) or both $(\mathbf{c}, \mathbf{f}, \mathbf{i})$. The arrowheads denote CaptureTec transfectant selection beads bound to cells. Original magnification $\times 40$; scale bar represents $5 \mu \mathrm{m}$.

in a time-dependent manner following MCSP clustering (Figure 1a). Furthermore, MCSP-induced phosphorylation of p130 was sensitive to genistein (Figure 1b), indicating that p130 tyrosine phosphorylation may influence MCSP-induced signal transduction leading to integrin-mediated cell spreading.

MCSP clustering induces $\mathrm{p} 130^{\text {cas }}$ recruitment and phosphorylation. We then re-immunoprecipitated MCSP-associated proteins with antibodies directed against various proteins of $M_{\mathrm{r}} 130 \mathrm{~K}$. A monoclonal antibody recognizing p130 cas immunoprecipitated a MCSP-associated protein of $M_{\mathrm{r}} 130 \mathrm{~K}$ (Figure 1c, lane 5). Although p130 ${ }^{\text {cas }}$ did not associate with MCSP in the absence of clustering, clustering of MCSP induced both the recruitment and the tyrosine phosphorylation of p130 cas (Figure 1c, d, lanes 3, 5). Clustering of another cell-surface receptor, the class I major histocompatability complex (MHC), by an isotype-matched monoclonal antibody did not induce $\mathrm{p} 130^{\mathrm{cas}}$ recruitment or tyrosine phosphorylation (Figure 1c, d, lanes 2, 4). These results indicate that, under these experimental conditions, recruitment and tyrosine phosphorylation of $\mathrm{p} 130^{\mathrm{cas}}$ specifically require MCSP stimulation.

p130 $^{\text {cas }}$ is required for MCSP-induced $\alpha_{4} \beta_{1}$-mediated cell spreading. We next evaluated the requirement for p130 cas in MCSP-induced melanoma-cell spreading by using a dominant-negative $\mathrm{p} 130^{\mathrm{cas}}$ $\mathrm{SH} 3$ construct that binds to a proline-rich span in proteins such as FAK $^{10}$. As reported previously, both untransfected and mock-transfected A375SM melanoma cells adhered but did not spread when either $\alpha_{4} \beta_{1}$ integrin or MCSP was engaged alone on rIIICS- or 9.2.27coated plates, respectively (Figure $2 \mathrm{a}, \mathrm{b}, \mathrm{d}, \mathrm{e})^{17}$. Only when MCSP and $\alpha_{4} \beta_{1}$ integrin were engaged cooperatively was cell spreading observed (Figure 2c, f). Cells transfected with the dominant-negative p130 ${ }^{\text {cas }} \mathrm{SH} 3$ construct were unable to spread on a substrate engaging both MCSP and $\alpha_{4} \beta_{1}$ integrin (Figure $2 \mathrm{~g}-\mathrm{i}$ ). To determine whether tyrosine phosphorylation of $\mathrm{p} 130^{\mathrm{cas}}$ was required for MCSP-induced cell spreading, we transfected cells with $\mathrm{p} 130^{\text {cas }}(\Delta \mathrm{SD})$, a mutated p130 cas that lacks residues 119-420, which include multiple YXXP motifs (single-letter amino-acid code) that function as tyrosine kinase substrates ${ }^{11,28}$. Cells transfected with $\mathrm{p} 130^{\text {cas }}(\Delta \mathrm{SD})$ failed to 

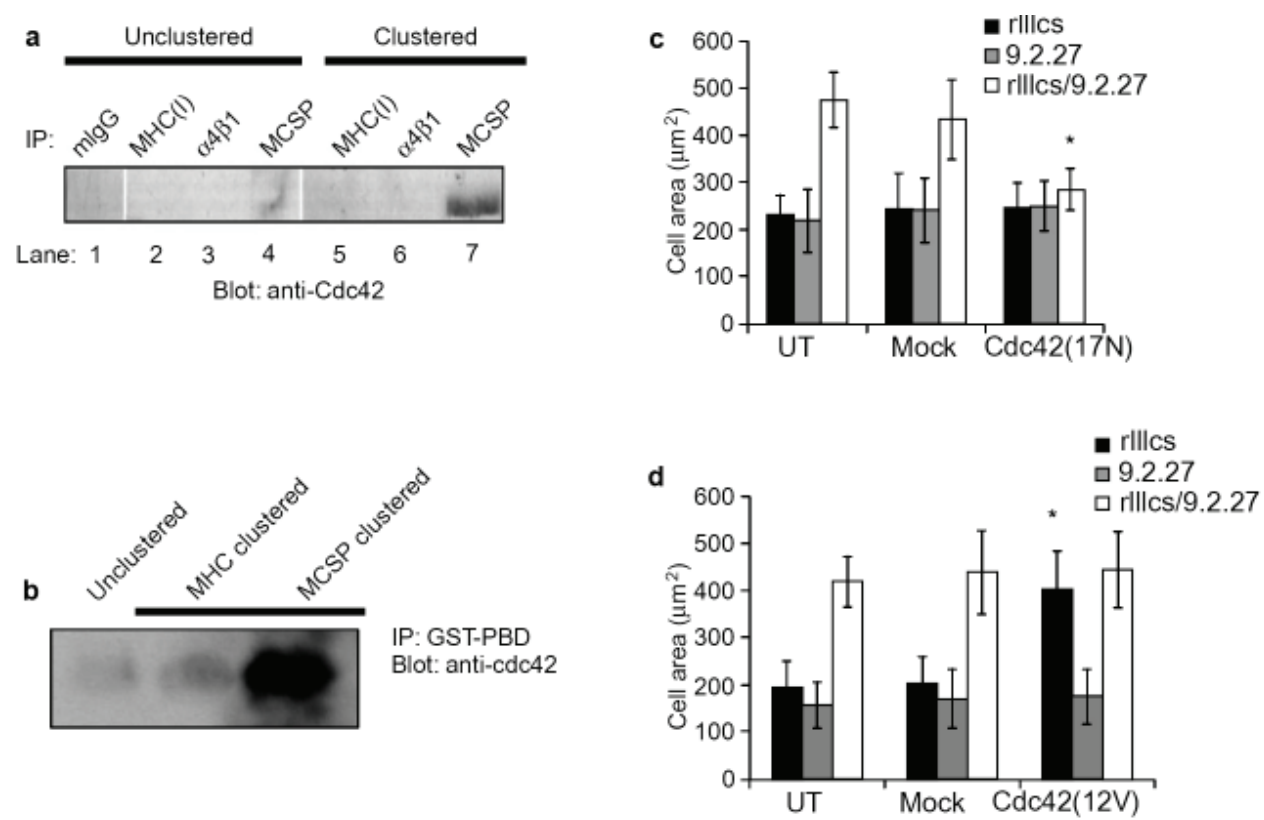

Figure 3 Activated Cdc42 associates with MCSP and induces spreading of melanoma cells. a, Clustering of MCSP specifically recruits Cdc42. b, Cdc42 is specifically activated upon stimulation of MCSP, as determined by interaction with PAK binding domain (PBD)-coated beads, which bind preferentially to active Cdc42 or Rac. c, d, Untransfected (UT) or vector-transfected (mock) A375SM cells (c, d), or A375SM cells transfected with dominant-negative Cdc42 (Cdc42(17N)) (c) or constitutively active Cdc42 (Cdc42(12V)) (d) were allowed to adhere and spread on plates coated with rlllcs, monoclonal antibody 9.2.27 or both rlllcs and 9.2.27. ${ }^{*} P<0.001$ compared with untransfected cells.

spread on a substrate engaging both MCSP and $\alpha_{4} \beta_{1}$ integrin (data not shown). Collectively, these data indicate that recruitment and tyrosine phosphorylation of $\mathrm{p} 130^{\text {cas }}$ function in mediating MCSP-induced signal-transduction pathways leading to $\alpha_{4} \beta_{1}$-integrin-dependent spreading of melanoma cells.

Cdc42 associates with MCSP upon MCSP clustering. Previous studies have localized MCSP to microspikes and filopodia of cultured melanoma cells, indicating that MCSP may mediate early cell-matrix recognition events important to the process of cell adhesion $^{29}$. As the Rho-family GTPase Cdc42 stimulates filopodia formation in fibroblasts ${ }^{21}$, we next determined whether Cdc42 associates with MCSP. We incubated A375SM melanoma cells with magnetic beads coated with monoclonal antibody 9.2 .27 or $\mathrm{P} 4 \mathrm{C} 2$ (anti- $\alpha_{4}$-integrin antibody), and analysed associated proteins for the presence of $\mathrm{Cdc} 42$ by immunoblotting. In the absence of adhesionreceptor clustering, $\mathrm{Cdc} 42$ showed a low level of constitutive association with MCSP but not with $\alpha_{4} \beta_{1}$ integrin (Figure 3a, lanes 3, 4). This association was markedly enhanced (about 4.4-fold, as determined by densitometry) upon MCSP clustering (Figure 3a, lane 7; data not shown). MCSP-associated Cdc42 represents $\sim 59 \%$ of total cellular $\mathrm{Cdc} 42$ (data not shown). Clustering of $\alpha_{4} \beta_{1}$ integrin, however, did not induce $\mathrm{Cdc} 42$ association with the integrin (Figure 3a, lane 6). We also determined the activation state of Cdc42 upon MCSP stimulation. Using the PAK binding domain (PBD) of PAK3, which binds preferentially to GTP-bound Cdc42 or Rac, we found that MCSP stimulation resulted in a rapid and robust activation of Cdc42 (Figure 3b). Furthermore, MHC stimulation did not induce Cdc42 activation (Figure 3b), indicating that MCSP activation of $\mathrm{Cdc} 42$ is specific.

To determine whether Cdc42 influences MCSP-induced signal transduction leading to $\alpha_{4} \beta_{1}$-integrin-dependent cell spreading, we transfected cells with expression vector alone or with constructs encoding Cdc42 as a dominant-negative (Cdc42(17N)) or constitutively active $(\mathrm{Cdc} 42(12 \mathrm{~V}))$ enzyme. We assayed transfected cells for cell spreading as described above. Unlike both untransfected and mock- transfected cells, cells transfected with Cdc42(17N) adhered but did not spread when both MCSP and $\alpha_{4} \beta_{1}$ integrin were engaged (Figure $3 c)$. Furthermore, melanoma cells transfected with Cdc42(12V) fully spread when $\alpha_{4} \beta_{1}$ integrin alone was engaged on rIIIcs-coated plates, bypassing the requirement for MCSP engagement in inducing $\alpha_{4} \beta_{1}$ integrin-mediated cell spreading (Figure $3 \mathrm{~d}$ ). Together, these data implicate $\mathrm{Cdc} 42$ in mediating post-adhesion cytoskeletal changes following engagement of MCSP and $\alpha_{4} \beta_{1}$ integrin in A375SM human melanoma cells.

Cdc42(17N) inhibits MCSP-induced p130 cas recruitment and phosphorylation. To assess the role of $\mathrm{Cdc} 42$ in signal transduction from MCSP, we studied the effects of mutant Cdc42 constructs on MCSP-induced recruitment and tyrosine phosphorylation of $\mathrm{p} 130^{\mathrm{cas}}$. Cells were transfected with either vector alone or $\operatorname{Cdc} 42(17 \mathrm{~N})$. Transfected cells were incubated with 9.2.27-coated magnetic beads to induce tyrosine phosphorylation of p130 cas . Melanoma cells expressing dominant-negative $\mathrm{Cdc} 42$ failed to recruit or tyrosine phosphorylate $130^{\text {cas }}$ upon MCSP stimulation (as compared with both mock-transfected and untransfected cells) (Figure 4a, b). Cells transfected with a constitutively active Cdc42 construct showed enhanced p130 ${ }^{\text {cas }}$ recruitment and subsequent tyrosine phosphorylation upon clustering of MCSP (data not shown). Hence, the GTPase Cdc42

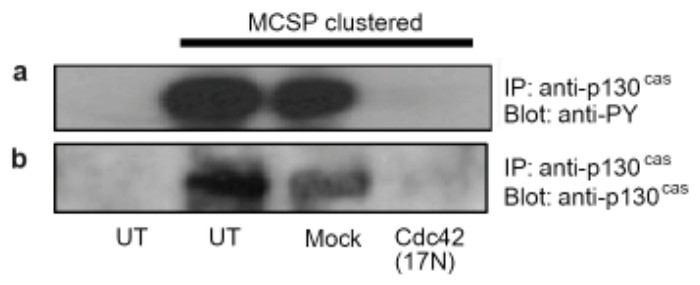

Figure 4 Cdc42 mediates MCSP-induced p130cas recruitment and tyrosine phosphorylation. A375SM cells that were untransfected (UT) or transfected with vector alone (mock) or dominant-negative Cdc42 (Cdc42(17N)) were incubated with beads coated with monoclonal antibody 9.2.27, which induced clustering of MCSP and tyrosine phosphorylation (a) and recruitment (b) of p130cas . 


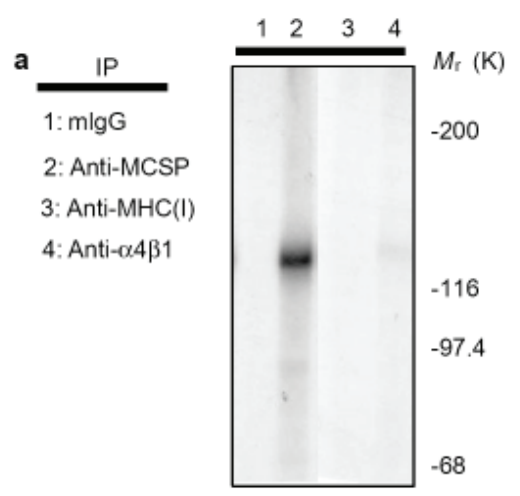

b

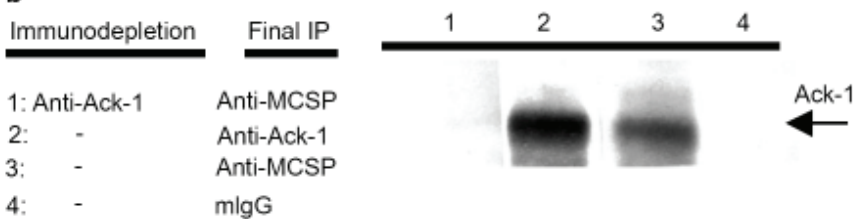

Figure 5 Ack- 1 kinase activity is associated with MCSP. a, In vitro kinase activity of a $120 \mathrm{~K}-130 \mathrm{~K}$ protein is specifically associated with MCSP. b. Immunodepleting Ack1 kinase from cell lysates subsequently ablates the 120K-130K MCSP-associated in vitro kinase activity.

is involved in activating MCSP induced tyrosine-kinase pathways that lead to the recruitment and tyrosine phosphorylation of $130^{\text {cas }}$.

Ack-1 associates with MCSP. As association of Cdc42 with MCSP induced tyrosine phosphorylation of $\mathrm{p} 130^{\mathrm{cas}}$, we proposed that activated Cdc42-associated kinase-1 (Ack-1) might mediate this phosphorylation. We lysed A375SM melanoma cells and immunoprecipitated proteins by using antibodies directed against MCSP, class I MHC or $\alpha_{4} \beta_{1}$ integrin under mild detergent conditions. Subsequent in vitro kinase assays (performed in the absence of exogenous sub-

a

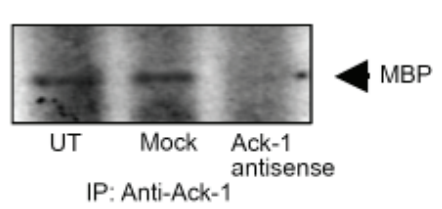

\section{b}
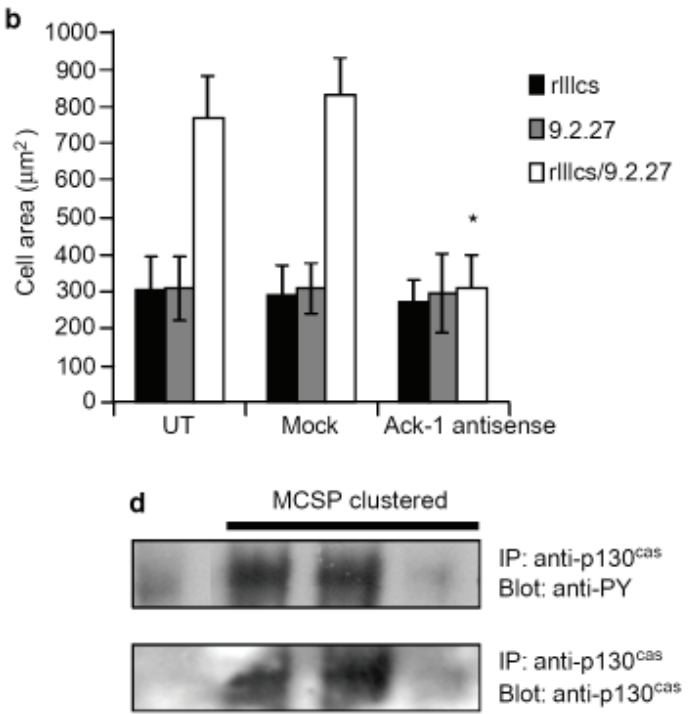

Figure 6 Ack-1 kinase induces spreading of melanoma cells and tyrosine phosphorylation of p130 cas. a, Expression of Ack-1 antisense vector inhibits Ack1 in vitro kinase activity, as determined by phosphorylation of an exogenous substrate, myelin basic protein (MBP). b. Untransfected A375SM cells (UT) or A375SM cells transfected with either vector alone (mock) or Ack-1 antisense vector were allowed to adhere and spread on plates coated with rlllcs, monoclonal antibody 9.2 .27 , or both. ${ }^{*} P<0.001$ compared with untransfected cells. c, Untransfected A375SM cells (UT) or A375SM cells transfected with vector alone (mock) or Ack-1 antisense vector were clustered with 9.2.27-coated beads to induce tyrosine phosphorylation of p130 cas $\mathbf{d}$. Untransfected A375SM cells (UT) or cells transfected with mock or Ack-1 kinase-dead (kd) vector were clustered with 9.2.27-coated beads to induce tyrosine phosphorylation and recruitment of p130'as. 
phorylation. Melanoma cells expressing Ack-1 antisense constructs failed to recruit and tyrosine phosphorylate $\mathrm{p} 130^{\text {cas }}$ upon MCSP clustering (Figure 6c), indicating that $\mathrm{p} 130^{\mathrm{cas}}$ may be a downstream target of Ack-1. To determine whether the kinase activity of Ack-1 is specifically required for signalling from MCSP, we transfected melanoma cells with a kinase-dead Ack-1 construct, Ack1(K163A) (Figure 6d). Cells transfected with this kinase-dead construct failed to either recruit or tyrosine phosphorylate p130 ${ }^{\text {cas }}$ upon MCSP clustering. Together, these data illustrate the importance of Ack-1 kinase activity in propagating MCSP-induced signal transduction, ultimately leading to $\alpha_{4} \beta_{1}$-integrin-mediated spreading of melanoma cells.

\section{Discussion}

Our previous studies showed that MCSP stimulates $\alpha_{4} \beta_{1}$-integrinmediated adhesion and spreading of melanoma cells ${ }^{16-19}$, in part through the involvement of activated tyrosine kinases ${ }^{17}$. Here, we have shown that signalling through MCSP induces the recruitment and tyrosine phosphorylation of $130^{\text {cas }}$. We propose a unique MCSP-induced signalling pathway that integrates both activated Cdc42 and Ack-1, thereby stimulating the downstream recruitment and tyrosine phosphorylation of $\mathrm{p} 130^{\text {cas }}$.

Using dominant-negative $\mathrm{p} 130^{\text {cas }}$ constructs, we showed that p130 ${ }^{\text {cas }}$ promotes MCSP-induced $\alpha_{4} \beta_{1}$-integrin-mediated cytoskeletal rearrangements. Phosphorylation of $\mathrm{p} 130^{\text {cas }}$ has been implicated in integrin-induced signal-transduction pathways; upon integrin engagement, $\mathrm{p} 130^{\mathrm{cas}}$ is tyrosine phosphorylated through interactions of FAK/Src with the SH3 domain of p130 cas (refs 28, 30, 31). p130 cas has also been localized to focal adhesions ${ }^{32}$. Furthermore, p $130^{\text {cas }}$ is involved both in FAK-mediated migration of $\mathrm{CHO}$ cells ${ }^{10}$ and in promoting integrin-dependent tumor-cell migration and invasion through coupling with $\mathrm{Crk}^{11}$. These results indicate that phosphorylation of p130 cas by multiple tyrosine kinases may be important for tumor invasion and metastasis by regulating cell adhesion and motility.

Using a metastatic melanoma cell line, we found that MCSP-induced tyrosine phosphorylation of $\mathrm{p} 130^{\text {cas }}$ is dependent on the recruitment and activation of the Rho-family GTPase Cdc42. Although $\mathrm{Cdc} 42$ is important for stimulating filopodia formation and maintaining cell polarity during cell migration ${ }^{21,33}$, emerging evidence also implicates activation of $\mathrm{Cdc} 42$ in cellular transformation and tumor progression. For instance, Cdc42 activation confers anchorage-independent growth of rat fibroblasts and is required for Ras-mediated transformation ${ }^{34}$. Furthermore, activation of $\mathrm{Cdc} 42$ promotes integrin-mediated motility and invasion of breast cancer cells ${ }^{23}$. On the basis of our results, we propose that MCSP enhances tumor cell invasion and metastasis by recruiting a signal-transduction complex that includes active $\mathrm{Cdc} 42$.

Our data also show that MCSP-induced sequestration of Cdc42 and tyrosine-phosphorylated $130^{\text {cas }}$ depends upon the activation of the kinase Ack-1. Ack-1 and Ack-2 associate with the GTP-bound form of Cdc42 (refs 25-27), and GTP-bound Cdc42 activates autophosphorylation of Ack-2 within cells ${ }^{26}$. It has, therefore, been proposed that GTP-bound Cdc42 mediates the activation of Ack kinases by directing their proper cellular localization ${ }^{26}$. The subcellular localization of Ack kinases by interactions with GTP-bound Cdc42 may enhance the ability of these kinases to recruit and/or phosphorylate target proteins, further propagating signal transduction.

Although MCSP can induce signals independently of integrin engagement, our data also indicate that the signals stimulated by MCSP are closely related and/or intersect integrin-mediated signal-transduction pathways. For example, tyrosine phosphorylation of p130 cas is also associated with ligation of $\beta_{1}$ integrin ${ }^{28,30,31,35,36}$, indicating that this adaptor protein may be involved in integrin-mediated adhesion and motility. Furthermore, Ack- 2 co-precipitates with $\beta_{1}$ integrin, and activation of Ack-2 is required for its association with this integrin ${ }^{27}$; however, a direct relationship between Ack-2 and downstream integrin targets such as $\mathrm{p} 130^{\text {cas }}$ or FAK has not been established. Nevertheless, it is possible that MCSP-and $\alpha_{4} \beta_{1}$ integrin-induced signalling pathways may intersect at multiple points. Such intersections may help to amplify these signalling pathways at cell-ECM attachment sites, which in turn act to accelerate cytoskeletal reorganization, leading to cell spreading, focal-contact formation and firm adhesion. Studies in which MCSP-induced signals are evaluated in the absence of functional integrin signalling (for example, using dominant-negative FAK) will be important in defining specific intersection points between MCSP and integrin signalling pathways. Present studies are also focusing on evaluating the potential involvement of other Rho-family GTPases (such as Rac1 and RhoA) in MCSP-induced signalling, as the activity of Rho-family GTPases can be coordinated in certain cell types ${ }^{21}$.

The structural features of MCSP that stimulate signal transduction are also being studied. Addition of chondroitin sulphate to the MCSP core protein confers on the proteoglycan the ability to interact with the C-terminal heparin-binding domain of fibronectin (and perhaps other matrix proteins). $\alpha_{4}$ integrin subunits also bind to chondroitin sulphate glycosaminoglycan (CSGAG) through a unique site on the integrin subunit, termed SG-1, and this interaction may enhance the activation of certain integrins ${ }^{19}$. CSGAG does not seem to be involved in MCSP-induced signal transduction, as both cell spreading and signalling are observed following CSGAG removal with chondroitinase $\mathrm{ABC}$ (J.I., unpublished observations). Instead, the data support a direct role for the MCSP core protein in signal transduction. Although the MCSP core protein has no apparent catalytic domains, the cytoplasmic tail of MCSP contains three potential threonine phosphorylation sites ${ }^{37}$. The importance of these sites has not yet been established; however, inhibitors of serine/threonine kinases (such as chelerythrine) inhibit MCSP-induced cell spreading (J.I., unpublished observations). Collectively, these results indicate that distinct structural features of MCSP may function to enhance adhesion of melanoma cells by both activating integrins and stimulating signalling pathways that lead to cytoskeletal rearrangement.

MCSP expression in melanoma cells is increased quite early in tumor progression ${ }^{13,38}$, indicating that it may also function in melanoma biology in ways that are related to cell growth and survival. For example, antibodies directed against MCSP inhibit anchorageindependent growth of human melanoma cells and suppress melanoma tumor growth in vivo ${ }^{39,40}$. Expression of NG2, the rat homologue of MCSP, may also increase both the in vivo tumorigenicity of melanoma cells in experimental metastasis models and the proliferation of B16 melanoma cells in vitro ${ }^{41}$. Cdc42 and Ack-2 have been linked to the activation of a subfamily of mitogen-activated protein kinases, the c-Jun amino-terminal kinases ( JNKs), and thereby may stimulate gene expression ${ }^{27,42,43}$. The sequestration/ activation of signalling complexes by MCSP may, therefore, stimulate critical signalling pathways important for controlling growth and programmed cell death.

\section{Methods}

\section{Cell culture.}

Highly metastatic A375SM human melanoma cells were selected by in vivo experimental metastasis assays of parent $\mathrm{A} 375 \mathrm{P}$ cells in nude mice and were provided by I.J. Fidler ${ }^{44}$. Cells were maintained in Eagle's minimal essential media (EMEM) supplemented with $10 \%$ fetal calf serum, $50 \mu \mathrm{gml}^{-1}$ gentamycin, minimal essential media vitamin solution and $1 \mathrm{mM}$ sodium pyruvate. These cells were routinely used before 15 cell passages.

\section{Antibodies.}

Monoclonal antibody 9.2.27, directed towards the MCSP core protein, was a gift 
from R. Reisfeld. The anti- $\alpha_{4}$-integrin monoclonal antibody $\mathrm{P} 4 \mathrm{C} 2$ was provided by E. Wayner. Anti-p130 $0^{\text {cas }}$ monoclonal antibody was purchased from Transduction Laboratories. Anti-Ack-1 polyclonal antibody sc-323 (Santa Cruz Laboratories) was raised against a C-terminal peptide fragment, NLEQAGCHLLGSWGPAHHKR (amino acids 1,072-1,091). Anti-Cdc42 monoclonal antibodies were obtained from Santa Cruz Laboratories. Monoclonal antibody against MHC class I molecules was obtained from Pharmingen.

\section{Plasmids.}

The full-length Ack-1 sequence was excised from the plasmid pBluescript SKAck-1 by digestion with $E c o \mathrm{RI}^{25}$. The purified fragment was then ligated into pBKRSV (Stratagene) digested with EcoRI. The ligated plasmid was then used to transform Escherichia coli strain DH5 $\alpha$. The purified plasmid was sequenced at the Microchemical Facility of the University of Minnesota to verify antisense orientation and was subsequently designated pBKRSV-Ack-1A.S. The pXJHAAck-1(K163A) kinase-inactive Ack-1 construct was a gift from E. Manser. Plasmids expressing glutathione-S-transferase (GST)-conjugated PBD were used to estimate the levels of Cdc42 activation as described ${ }^{45}$. Dominant-negative Cdc42 (Cdc $42(17 \mathrm{~N}))$ and constitutively active $\mathrm{Cdc} 42(\mathrm{Cdc} 42(12 \mathrm{~V}))$ in pZip were gifts from C. Der. The pKHSH3 ${ }^{\text {cas }}$ construct was generated as described ${ }^{10}$. pcDL-SR $\alpha-p 130^{\text {cas }}(\Delta \mathrm{SD})$ was generated as described ${ }^{28}$. The p130 $0^{\text {cas }}(\Delta \mathrm{SD})$ insert was liberated from the pcDL-SR $\alpha$ vector by $S a l I / E c o$ RI digestion and was ligated into SalI/EcoRI-digested pBKRSV (Stratagene). The reporter plasmid pHook-1 was purchased from Invitrogen.

\section{Transfections and selection.}

Cells were grown in six-well plates to about $60 \%$ confluency. Cells were then transfected with $2 \mu \mathrm{g}$ of the vector of interest along with $1 \mu \mathrm{g}$ pHook selection vector using the clonfectin transfection reagent (Clontech). Briefly, transfection media containing $3 \mu \mathrm{g}$ clonfectin and plasmids were mixed in serum-free EMEM for $30 \mathrm{~min}$, after which the transfection media were applied to the cells. Transfection media were removed $3 \mathrm{~h}$ later and replaced with standard growth media. $36 \mathrm{~h}$ later, melanoma cells were collected with PBS/1mM EDTA and washed several times in serum-free EMEM. Cells were then mixed with CaptureTec selection beads (Invitrogen) for $30 \mathrm{~min}$ at $37^{\circ} \mathrm{C}$; the transfected cells were removed through magnetic separation. Selected cells were washed twice in serumfree media and used immediately in experiments.

\section{Preparation of recombinant CS1 (rlllcs).}

Recombinant CS1 (rIIIcs), representing the alternatively spliced type IIICS domain of human fibronectin, was prepared as described below. A plasmid encoding the C-terminal portion of cellular fibronectin, provided by M.-L. Chu, served as a template for amplification by the polymerase chain reaction (PCR). Synthetic oligonucleotides complementary to fibronectin nucleotides 5,881-5,901 $\left(5^{\prime}\right)$ and 6,184-6,204 (3') and containing 5' BamHI/3' EcoRI sites were used as primers for PCR to generate the DNA encoding the type IIICS $\alpha_{4} \beta_{1}$-integrinbinding sequence. Template DNA and $1 \mu \mathrm{gml}^{-1}$ primer were mixed with $1 \times \mathrm{PCR}$ reaction buffer containing $1.5 \mathrm{mM} \mathrm{MgCl}_{2}$ and denatured for $5 \mathrm{~min}$ at $95^{\circ} \mathrm{C}$. PCR was performed for 30 cycles of the following sequence: $60 \mathrm{~s}$ at $62^{\circ} \mathrm{C}, 90 \mathrm{~s}$ at $72^{\circ} \mathrm{C}$, and $60 \mathrm{~s}$ at $95^{\circ} \mathrm{C}$, followed by a final, 5 -min extension at $72^{\circ} \mathrm{C}$. The PCR product was ligated into the pGEX-2T vector through the EcoRI and BamHI sites and verified by sequencing. The resulting plasmid encoding the GST-IIICS fusion protein was used to transform E. coli strain BL21(DE3) (Stratagene). Overnight cultures were diluted 1:10 in fresh LB media containing $50 \mu \mathrm{g} \mathrm{ml}^{-}$ ${ }^{1}$ ampicillin and incubated for $1 \mathrm{~h}$ at $37^{\circ} \mathrm{C}$. Protein synthesis was induced by the addition of isopropyl- $\beta$-D-thiogalactoside (IPTG) to $1 \mathrm{mM}$ for $2.5 \mathrm{~h}$ at $37^{\circ} \mathrm{C}$. Following centrifugation, the bacterial pellets were resuspended in 1:200 volume cold extraction buffer (PBS, $1 \%$ Triton-X100, 0.1\% SDS, 10mM EDTA, 1mM phenylmethylsulphonyl fluoride (PMSF), $1 \mathrm{mM}$ NEM, plus $20 \mu \mathrm{g} \mathrm{ml}^{-1}$ each of antipain, aprotinin and leupeptin) and subjected to brief sonication on ice. The insoluble cell debris were removed by centrifugation and the cleared supernatant added to a glutathione-Sepharose affinity column that was equilibrated with phosphate buffered saline (PBS). The column was washed with $50 \mathrm{ml} 50 \mathrm{mM}$ Tris $\mathrm{HCl}$, pH 7.4. The GST-IIICS fusion protein was then eluted with $5 \mathrm{mM}$ reduced glutathione in $50 \mathrm{mM}$ Tris- $\mathrm{HCl}$ at $\mathrm{pH}$ 7.4. Finally, the eluted protein was assayed for purity and molecular weight by SDS-PAGE.

\section{Cell-spreading assays.}

Cells were collected with PBS/1mM EDTA and washed twice with serum-free EMEM. Cells were adjusted to a final concentration of $5 \times 10^{4}$ cells ml $^{-1}$ in serum-free EMEM. $5 \times 10^{3}$ cells were added to each well of 96 -well plates coated with rIIIcs, monoclonal antibody 9.2.27, or both. The cells were incubated at $37^{\circ} \mathrm{C}$ for $60 \mathrm{~min}$ and washed gently with serum-free EMEM. Cells were fixed and stained using DiffQuik solutions (Baxter Inc., Miami, FL). Occupied cell areas were quantified under a microscope at a magnification of $\times 40$. Cell borders were traced electronically; the areas were calculated using a Semi Automatic Image Analysis System (Optomax Inc., Hollis, NH). Statistical significance was determined using Student's $t$-test.

\section{Cdc42 activity assay.}

GST-PBD beads were prepared as described ${ }^{46,47}$. Cdc42 activity was assayed as described ${ }^{46,47}$ with minor modifications. Briefly, A375SM cells were collected in $3 \mathrm{mM}$ EDTA/PBS and were washed twice in serum-free media and divided into equal aliquots, each containing $5 \times 10^{5}$ cells. MCSP was clustered with antibody-coated magnetic beads as described above. RIPA buffer $(500 \mathrm{mM} \mathrm{NaCl}$, $1 \%$ NP- $0,0.5 \%$ deoxycholate, $0.1 \%$ SDS, $50 \mathrm{mM}$ Tris, pH $8.0,10 \mathrm{mM} \mathrm{MgCl}_{2}$, $1 \mathrm{mM}$ PMSF, $1 \mathrm{mM}$ NEM, and $0.1 \mathrm{mM}$ pervanadate) was added to cell-bead conjugates; this step was followed by brief sonication and centrifugation. Lysates were normalized for protein content and were added to $20 \mu \mathrm{g}$ GST-PBD beads, then incubated at $4^{\circ} \mathrm{C}$ with shaking for $30 \mathrm{~min}$. Beads were washed 3-5 times in HBS wash buffer (20 mM HEPES, pH 7.5, 120mM NaCl, 1\% NP-40, $10 \mathrm{mM}$ $\mathrm{MgCl}_{2}$ ). Samples were reduced and electrophoresed in $15 \%$ SDS-PAGE, and visualized by western blotting using anti-Cdc 42 monoclonal antibodies (see text).

\section{In vitro kinase assays.}

Cells $\left(2 \times 10^{6}\right)$ were lysed in immunoprecipitation buffer $(50 \mathrm{mM}$ Tris-HCl, $\mathrm{pH}$ 7.3, containing $1 \%$ Brij 58, $0.15 \mathrm{M} \mathrm{NaCl}, 2 \mathrm{mM} \mathrm{MgCl}, 1 \mathrm{mM}$ PMSF, $1 \mathrm{mM}$ NEM and $0.1 \mathrm{mM}$ pervanadate). Lysates were precleared and immunoprecipitated for $4 \mathrm{~h}$ at $4^{\circ} \mathrm{C}$ using the appropriate antibodies conjugated to protein-Gagarose beads. The beads were washed four times with wash buffer $(20 \mathrm{mM}$ Tris-HCl, $\mathrm{pH}$ 8.2, $150 \mathrm{mM} \mathrm{NaCl}, 2 \mathrm{mM} \mathrm{MgCl}, 1$ mM PMSF, 1 mM NEM, 0.1 $\mathrm{mM}$ pervanadate and $0.5 \%$ Brij 58 ). The beads were then washed in $\mathrm{NH}$ buffer (40 mM HEPES, $\mathrm{pH} 7.2,150 \mathrm{mM} \mathrm{NaCl}, 0.1 \mathrm{mM}$ pervanadate). The beads were resuspended in $\mathrm{NH}$ buffer and incubated for $10 \mathrm{~min}$ at room temperature with labelling buffer containing $10 \mathrm{mM}$ Tris, $\mathrm{pH} 7.4,10 \mathrm{mM} \mathrm{MgCl} 2,0.1 \mathrm{mM}$ pervanadate, $10 \mu \mathrm{Ci}\left[\gamma_{-}{ }^{32} \mathrm{P}\right] \mathrm{ATP}$ (ICN). When examining phosphorylation of exogenous substrates, we added $10 \mu \mathrm{g}$ MBP to the labelling buffer.

Radiolabelled proteins were separated by SDS-PAGE using a 7.5\% running gel and a 5\% stacking gel under reducing conditions and visualized by autoradiography.

\section{Co-immunoprecipitation, SDS-PAGE and western blotting.}

Cells $\left(2 \times 10^{6}\right)$ were incubated with 9.2.27-, P4C2-, or anti-MHC I-coated magnetic beads (Dynal) at a ratio of 50 beads per cell for $3-5$ min at $37^{\circ} \mathrm{C}$. Cellbead aggregates were collected on a magnet and lysed for $20 \mathrm{~min}$ at $4^{\circ} \mathrm{C}$ in lysis buffer containing $50 \mathrm{mM}$ Tris-HCl, $\mathrm{pH} 7.3,1 \%$ Brij 58, $0.15 \mathrm{M} \mathrm{NaCl}, 1 \mathrm{mM}$ PMSF, $1 \mathrm{mM}$ NEM and $1 \mathrm{mM}$ pervanadate. The bead-protein complexes were washed with lysis buffer and associated proteins released by brief sonication in $1 \%$ SDS. The solution was diluted in immunoprecipitation buffer containing $1 \%$ Triton-X100, $0.15 \mathrm{M} \mathrm{NaCl}, 1 \mathrm{mM}$ PMSF, $1 \mathrm{mM}$ NEM and $1 \mathrm{mM}$ pervanadate. The proteins were then immunoprecipitated using various antibodies, separated on $7.5 \%$ or $15 \%$ separating gels with $5 \%$ stacking gel, and transferred to Immobilon-P membrane. The membranes were blocked in PBS containing $1.5 \%$ BSA at $4^{\circ} \mathrm{C}$ overnight. Membranes were incubated with the appropriate antibodies for $1 \mathrm{~h}$ at room temperature, washed with PBS containing $0.5 \%$ Tween 20 and incubated with horseradish-peroxidase-conjugated secondary $\operatorname{IgG}(1: 1,000)$ for $1 \mathrm{~h}$ at room temperature. The membrane was extensively washed and proteins detected with the enhanced chemiluminescence (ECL) system (Amersham).

\section{References}

1. Hynes, R. O. Integrins: versatility, modulation, and signaling in cell adhesion. Cell 69, 443-475 (1992).

2. McCarthy, J. B., Skubitz, A. P., Palm, S. L., \& Furcht, L. T. Metastasis inhibition of different tumor types by purified laminin fragments and a heparin binding fragment of fibronectin. J. Natl Cancer Inst. 80, 108-116 (1988).

3. Garofolo, A. et al. Involvement of the very late antigen 4 integrin on melanoma in interleukin-laugmented experimental metastasis. Cancer Res. 55, 414-419 (1995).

4. Taichman, D. B. et al. Tumor cell surface alpha4beta1 integrin mediates adhesion to vascular endothelium: demonstration of an interaction with the Nterminal domains of INCAM-110/VCAM-1. Cell Reg. 2, 347-355 (1991).

5. Rice, G. E., Gimbrone, M. A. \& Bevilacqua, M. P. Tumor cell-endothelial interactions. Am. J. Pathol. 133, 204-210 (1988). 
6. Gehlsen, K. R., Davis, G. E. \& Sriramaroa, P. Integrin expression in human melanoma cells with differing invasive and metastatic properties. Clin. Exp. Met. 10, 111-120 (1992).

7. Burridge, K., Turner, C. E. \& Romer, L. H. Tyrosine phosphorylation of paxillin and pp125FAK accompanies cell adhesion to extracellular matrix: a role in cytoskeletal assembly. J. Cell Biol. 119, 893-903 (1992).

8. LaFlamme, S. E. \& Auer, K. L. Integrin signaling. Semin. Cancer Biol. 7, 111-118 (1996).

9. Parsons, J. T. Integrin-mediated signalling: regulation by protein tyrosine kinases and small GTP-binding proteins. Curr. Opin. Cell Biol. 8, 146-152 (1996).

10. Cary, L. A., Han, D. C., Polte, T. R., Hanks, S. K. \& Guan, J.-L. Identification of 130CAS as a mediator of focal adhesion kinase-promoted cell migration. J. Cell Biol. 140, 211-221 (1998).

11. Klemke, R. L. et al. CAS/Crk coupling serves as a "molecular switch" for induction of cell migration. J. Cell Biol. 140, 961-972 (1998).

12. Delisser, H. M. et al. Platelet/endothelial cell adhesion molecule-1 (CD31)mediated cellular aggregation involves cell surface glycosaminoglycans. $J$. Biol. Chem. 268, 16037-16046 (1993).

13. Reisfeld, R. A. \& Cheresh, D. A. Human tumor antigens. Adv. Immunol. 40, 323-377 (1987).

14. Harper, J. R., Bumol, T. F. \& Reisfeld, R. A. Characterization of monoclonal antibody 155.8 and partial characterization of its proteoglycan antigen on human melanoma cells. J. Biol. Chem. 132, 2096-2104 (1984).

15. De Vries, J. E. et al. Characterization of melanoma-associated surface antigens involved in the adhesion and motility of human melanoma cells. Int. J. Cancer 38, 465-473 (1986).

16. Iida, J., Milius, R. P., Oegema, T. R., Furcht, L. T. \& McCarthy, J. B. Role of cell surface proteoglycans in tumor cell recognition of fibronectin. Trends Glycosci. Glycotechnol. 6, 1-16 (1994).

17. Iida, J. et al. Spreading and focal contact formation of human melanoma cells in response to the stimulation of both melanoma-associated proteoglycan (NG2) and alpha4beta1 integrin. Cancer Res. 55, 2177-2185 (1995).

18. Iida, J., Meijne, A. M. L., Knutson, J. R., Furcht, L. T. \& McCarthy, J. B. Cell surface chondroitin sulfate proteoglycans in tumor cell adhesion, motility, and invasion. Semin. Cancer Biol. 7, 155-162 (1996).

19. Iida, J. et al. A role for chondroitin sulfate glycosaminoglycan binding site in $\alpha 4 \beta 1$ integrin-mediated melanoma cell adhesion. J. Biol. Chem. 273, 5955-5962 (1998).

20. Ridley, A. J. \& Hall, A. The small GTP-binding protein rho regulates the assembly of focal adhesions and actin stress fibers in response to growth factors. Cell 70, 389-399 (1992).

21. Nobes, C. D. \& Hall, A. Rho, rac, and cdc42 GTPases regulate the assembly of multimolecular focal complexes associated with actin stress fibers, lamellipodia, and filopodia. Cell 81, 53-62 (1995).

22. Saoncella, S. et al. Syndecan-4 signals cooperatively with integrins in a Rho-dependent manner in the assembly of focal adhesions and stress fibers. Proc. Natl Acad. Sci. USA 96, 2805-2810 (1999).

23. Keely, P. J., Westwick, J. K., Whitehead, I. P., Der, C. J. \& Parise, L. V. $\mathrm{Cdc} 42$ and Rac1 induce integrin-mediated cell motility and invasiveness via PI 3-kinase. Nature 390, 632-636 (1997).

24. Hildebrand, J. D., Taylor, J. M. \& Parsons, J. T. An SH3 domain-containing GTPase-activating protein for Rho and $\mathrm{Cdc} 42$ associates with focal adhesion kinase. Mol. Cell. Biol. 16, 3169-3178 (1996).

25. Manser, E., Leung, T., Salhuddin, H., Tan, L. \& Lim, L. A non-receptor tyrosine kinase that inhibits the GTPase activity of p21cdc42. Nature 363, 364-367 (1993).

26. Yang, W. \& Cerione, R. A. Cloning and characterization of a novel Cdc42associated tyrosine kinase, ACK-2, from bovine brain. J. Biol. Chem. 272, 24819-24824 (1997).

27. Yang, W., Lin, Q., Guan, J. L. \& Cerione, R. A. Activation of the Cdc42associated tyrosine kinase-2 (ACK-2) by cell adhesion via integrin $\beta 1 . J$. Biol. Chem. 274, 8524-8530 (1999).

28. Tachibana, K. et al. Tyrosine phosphorylation of Crk-associated substrates by focal adhesion kinase. J. Biol. Chem. 272, 29083-29090 (1997).
29. Garrigues, H. J. et al. The melanoma proteoglycan: restricted expression on microspikes, a specific microdomain of the cell surface. J. Cell Biol. 103, 1699-1710 (1986).

30. Polte, T. R. \& Hanks, S. K. Interaction between focal adhesion kinase and Crk-associated tyrosine kinase substrate p130 cas. Proc. Natl Acad. Sci. USA 92, 10678-10682 (1995).

31. Harte, M. T., Hildebrand, J. D., Burnham, M. R., Bouton, A. H. \& Parsons, J. T. p130 cas, a substrate associated with v-Src and v-Crk, localizes to focal adhesions and binds to focal adhesion kinase. J. Biol. Chem. 271, 1364913655 (1996).

32. Nakamoto, T. et al. Requirements for localizations of $\mathrm{p} 130^{\text {cas }}$ to focal adhesions. Mol. Cell. Biol. 17, 3884-3887 (1997).

33. Nobes, C. \& Hall, A. Regulation and function of the Rho subfamily of small GTPases. Curr. Opin. Genet. Dev. 4, 77-81 (1994).

34. Qui, R. G., Abo, A., McCormick, F. \& Symons, M. Cdc42 regulates anchorage-independent growth and is necessary for Ras transformation. Mol. Cell. Biol. 17, 3449-3458 (1997).

35. Nojima, Y. et al. Integrin-mediated cell adhesion promotes tyrosine phosphorylation of $130^{\text {cas }}$, a Src homology 3-containing molecule having multiple Src homology 2-binding motifs. J. Biol. Chem. 270, 15398-15402 (1995).

36. Vuori, K. \& Ruoslahti, E. Tyrosine phosphorylation of p $130^{\text {cas }}$ and cortactin accompanies integrinmediated cell adhesion to extracellular matrix. J. Biol. Chem. 270, 22259-22262 (1995).

37. Pluschke, G. et al. Molecular cloning of a human melanoma-associated chondroitin sulfate proteoglycan. Proc. Natl Acad. Sci. USA 93, 9710-9715 (1996).

38. Satyamoorthy, K. et al. Melanoma cell lines from different stages of progression and their biological and molecular analyses. Melanoma Res. 7(Suppl 2), 35-42 (1997).

39. Harper, J. R. \& Reisfeld, R. A. Inhibition of anchorage-independent growth of human melanoma cells by a monoclonal antibody to a chondroitin sulfate proteoglycan. J. Natl Cancer Inst. 71, 259-263 (1983).

40. Bumol, T. F., Wang, Q. C., Reisfeld, R. A. \& Kaplan, N. O. Monoclonal antibody and an antibody-toxin conjugate to a cell surface proteoglycan of melanoma cells suppress in vivo tumor growth. Proc. Natl Acad. Sci. USA 80, 529-533 (1983).

41. Burg, M. A., Grako, K. A. \& Stallcup, W. B. Expression of the NG2 proteoglycan enhances the growth and metastatic properties of melanoma cells. $J$. Cell. Phys. 177, 299-312 (1998).

42. Teramoto, H. et al. The small GTP-binding protein rho activates c-Jun Nterminal kinases/stressactivated protein kinases in human kidney $293 \mathrm{~T}$ cells. Evidence for a Pak-independent signaling pathway. J. Biol. Chem. 271, 27225-27228 (1996).

43. Kyriakis, J. M. et al. The stress-activated protein kinase subfamily of c-Jun kinases. Nature 369, 156- 160 (1994).

44. Fidler, I. J. Rationale and methods for the use of nude mice to study the biology and therapy of human cancer metastasis. Cancer Metastasis Rev. 5, 29-49 (1986).

45. Bagrodia, S., Taylor, S. J., Creasy, C. L., Chernoff, J. \& Cerione, R. A. Identification of a mouse $\mathrm{p} 21 \mathrm{Cdc} 2 / \mathrm{Rac}$ activated kinase. J. Biol. Chem. 270, 22731-22737 (1995).

46. Taylor, S. J. \& Shalloway, D. Cell cycle-dependent activation of Ras. Curr. Biol. 6, 1621-1627 (1996).

47. Bagrodia, S., Taylor, S. J., Jordon, K. A., Van Aelst, L. \& Cerione, R. A. A novel regulator of p21activated kinases. J. Biol. Chem. 273, 23633-23636 (1998).

\section{ACKNOWLEDGEMENTS}

We thank Y. Shimizu for valuable discussions. This work was supported by grant CA21463 from the NIH (to L.T.F.). L.T.F. is a recipient of an Allen-Pardee professorship in cancer biology. 